\section{Karapandzic flap as most ade- quate surgical approach for squamous cell carcinoma of the lower lip}

Ilia Lozev, ${ }^{1}$ Ivan Pidakev, ${ }^{1}$

Ilia Batashki, ${ }^{2}$ Lorraine J. Kandathil, ${ }^{3}$ Nikhil Oliveira, ${ }^{3}$ Georgi Tchernev ${ }^{3,4}$

${ }^{1}$ Department of Common and Vascular Surgery, Medical Institute of Ministry of Interior, Sofia; ${ }^{2}$ Director of the Medical Institute of Ministry of Interior, Sofia; ${ }^{3}$ Onkoderma - Clinic for Dermatology, Venereology and Dermatologic Surgery, Sofia; ${ }^{4}$ Department of Dermatology, Venereology and Dermatologic Surgery, Medical Institute of Ministry of Interior, Sofia, Bulgaria

We present an 80-year-old patient with a fast-growing lesion on the lower lip, lasting for no longer than one year (Figure 1a). The clinical examination revealed the presence of endophytically growing tumour formation along almost the entire length of the
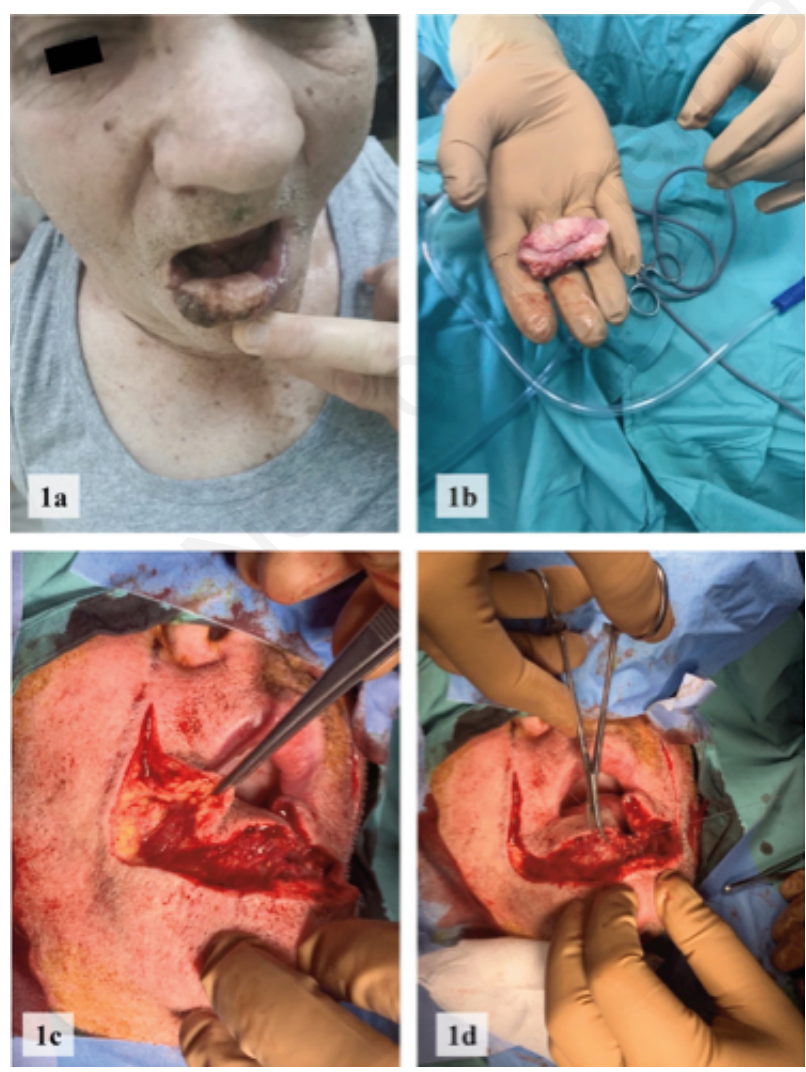

Figure 1. a) Plaque-like tumor formation, occupying about $2 / 3$ of the lower lip. b) Surgical excision of subsequent squamous cell carcinoma of the lower lip with a surgical safety margin of $1 \mathrm{~cm}$ in all directions. c,d) Careful dissection of the lateral flap in the area of the nasolabial fold/ bilateral and transposition of the flap to the middle of the face in order to cover the resulting intraoperative defect.

lower lip, associated with spontaneous bleeding as well as severe pain on palpation (Figure 1a). The suspicions for the diagnosis were mainly in favor of squamous cell carcinoma of the lower lip. The known concomitant diseases are angina pectoris, insulin-dependent diabetes mellitus and diabetic retinopathy. The surgery was performed under general anesthesia. Initially a skin incision was performed on the periphery of the orbicularis oris, then under the incision was infiltrated adrenaline diluted in physiological serum 1: 200,000. The tumor formation located on the upper surface of the lower lip was excised with a resection field of $1 \mathrm{~cm}$ in all directions. More than 2/3 of the lower lip was resected in parallel with the tumor formation (Figure 1b). We moved on to lower lip plastic with mobilization and relocation of the adjacent tissues by the Karapandzic method (Figure 1c-d). After hemostasis, layer by layer was passed through the skin, musculo-aponeurotic complex and superficial fascia along the course of the pre-drawn skin incision marginal branch of the facial nerve, the buccal branches of the facial nerve and the infe(Figure 1c-d). The nerve branches from the

This work is licensed under a Creative Commons Attribution-NonCommercial 4.0 International License (CC BY-NC 4.0).

\author{
Copyright: the Author(s), 2022 \\ Licensee PAGEPress, Italy \\ Dermatology Reports 2022; 14:9439 \\ doi:10.4081/dr.2022.9439
}

Publisher's note: All claims expressed in this article are solely those of the authors and do not necessarily represent those of their affiliated organizations, or those of the publisher, the editors and the reviewers. Any product that may be evaluated in this article or claim that may be made by its manufacturer is not guaranteed or endorsed by the publisher.

rior and upper labial branches of the facial artery were carefully presented and preserved. After the mobilization of the two wound surfaces of the lower lip, we proceeded to its layer-by-layer recovery. The integrity of the lower lip was restored, which was done with single sutures of the mucosa and of the orbicularis oris with resorbable sutures. The skin edges were repaired with single stitches with polypropylene 4/0 (Figure 2a). The histopathological finding showed evidence of keratinizing squamous cell carcinoma G2 with extensive superficial ulceration and deep infiltration of the muscle layer to the small salivary glands without infiltrating them. Tumor dimensions: 40 by $30 \mathrm{~mm}$. 
The histopathologically established margins of distance from the tumor tissue were 10 and $5 \mathrm{~mm}$, respectively. The performed diagnostic tests were without data for locoregional or distant metastases. The postoperative period passed without complications and the patient was referred for registration and follow-up at the regional oncology dispensary (Figure 2b). A 6-week follow-up showed signs of complete wound healing (Figure 3).

Reconstruction of the lower lip in patients with epithelial skin tumors, but not only, is a serious challenge and often requires a multidisciplinary approach. ${ }^{1}$ The lip area is of particular importance for each individual, as its role is multifunctional and is considered key in terms of the formation of speech, sound, food intake, but also the lips are perceived as a symbol of sexuality and sensuality. ${ }^{1}$

The first data on surgical reconstruction of the lips date from $1000 \mathrm{BC}$ in the notes of Sanskrit (language) from Susruta, ancient India. ${ }^{1}$ Other interesting data on V-shaped reconstruction of the lips date back to 1768 by Luis. ${ }^{2}$ Corrections of lip defects have been a priority since ancient times, as evidenced by a number of literature data. ${ }^{2}$

In cases where about $2 / 3$ of the lower lip is affected, the defects could be corrected by a limited number of plastics such as:
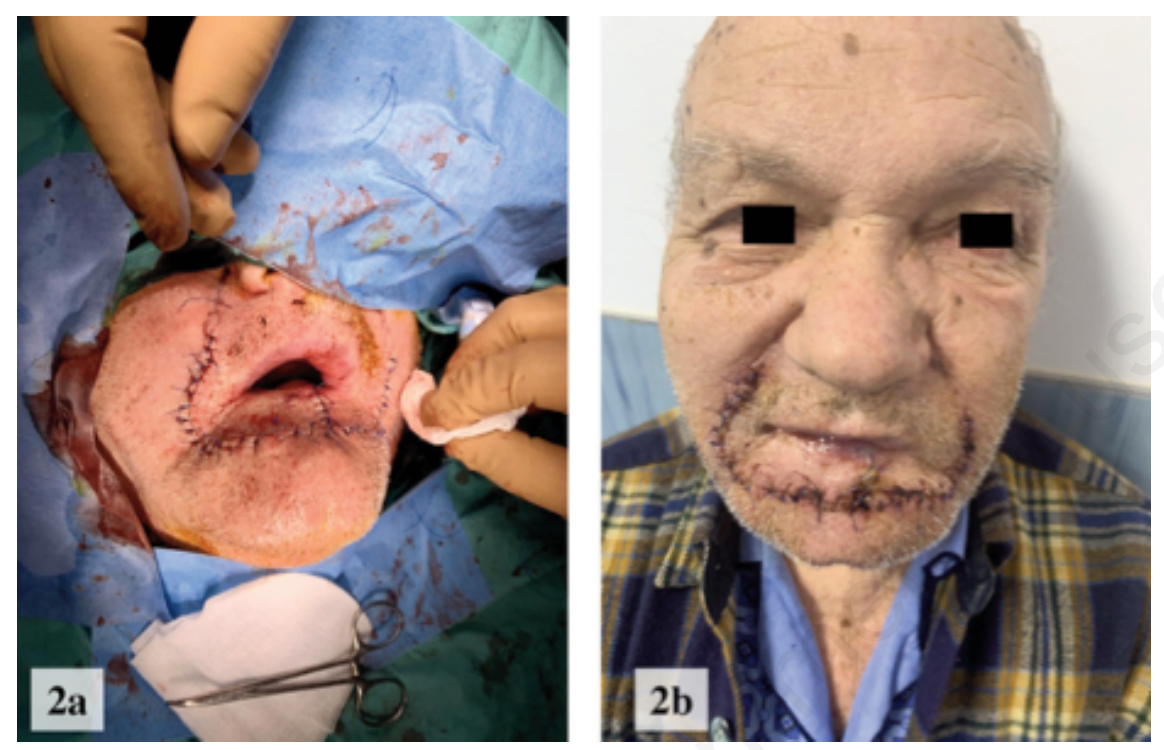

Figure 2. a) Postoperative status after adaptation of the wound edges after Karapandzic plastic surgery for the treatment of lower lip cancer. b) Postoperative effect on day 14 after surgery. Preserved function of sensitivity and motility of the lip. Lack of pain symptoms.
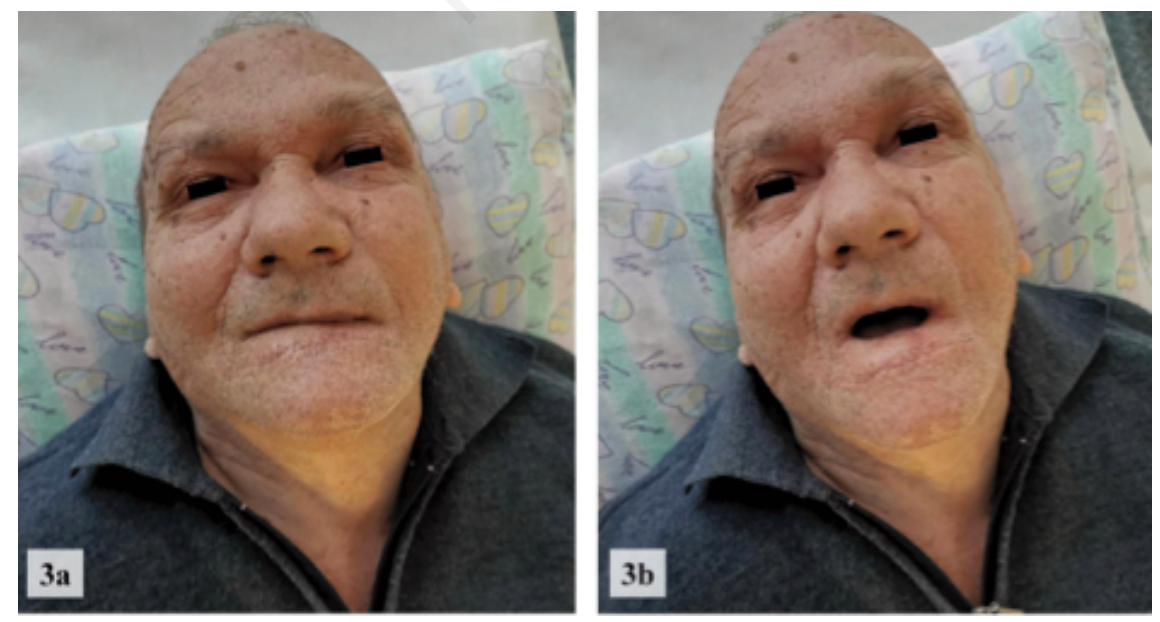

Figure 3. A 6-week follow up with signs of complete wound healing.

Karapandzic, Abbe or Estlander flaps. ${ }^{3}$ When the commissure is affected, the number of surgical plastics that could be used decreases significantly and the most applicable are two of the already mentioned plastics - those of Karapandzic or Estlander. ${ }^{3}$

When affecting about $3 / 4$ from the lower lip, according to a number of authors, Karapandzic flap is preferable, although a slight difficulty in food and fluid intake may occur due to the risk of postoperative microstomy. ${ }^{3}$ One of the great advantages of this technique is the preservation of the labial sphincter, its sensitivity and vascularization. ${ }^{4}$

In conclusion, we present a patient with an ulcerative form of SCC on the lower lip, successfully treated with Karapandzic flap. An excellent postoperative result was achieved, allowing the preservation of the integrity of the lower lip, as well as its functionality.

\section{References}

1. Singh AK, Kar IB, Mishra N, Raut S. Karapandzic Flap in Reconstruction of Post-traumatic Lower Lip Defects: Report of Two Cases. J Maxillofac Oral Surg 2015;14:858-61.

2. Mazzola RF, Lupo G. Evolving concepts in lip reconstruction. Clin Plast Surg 1984;11:583-617.

3. Khan AA, Kulkarni JV. Karapandzic flap. Indian J Dent 2014;5:107-9.

4. Espitalier F, Dréno B, Malard O. Place du lambeau de Karapandzic pour la reconstruction des pertes de substance étendues de la lèvre inférieure [Karapandzic flap for reconstruction of extensive defects of the lower lip]. Rev Laryngol Otol Rhinol (Bord) 2013;134:199-202. 